\title{
EFFECT OF MULTI-GRIP MYOELECTRIC PROSTHETIC HANDS ON DAILY ACTIVITIES, PAIN-RELATED DISABILITY AND PROSTHESIS USE COMPARED WITH SINGLE-GRIP MYOELECTRIC PROSTHESES: A SINGLE-CASE STUDY
}

\author{
Cathrine WIDEHAMMAR, PhD ${ }^{1,2}$, Ayako HIYOSHI, PhD ${ }^{3}$, Kajsa LIDSTRÖM HOLMQVIST, PhD2,4 , Helen LINDNER, PhD 5 \\ and Liselotte HERMANSSON, PhD ${ }^{2,6}$ \\ From the ${ }^{1}$ Department of Pediatrics, Faculty of Medicine and Health, ${ }^{2}$ University Health Care Research Center, Faculty of Medicine and \\ Health, ${ }^{3}$ Clinical Epidemiology and Biostatistics, School of Medical Sciences, ${ }^{4}$ Department of Neurology and Rehabilitation Medicine, \\ Faculty of Medicine and Health, ${ }^{5}$ School of Health Sciences and ${ }^{6}$ Department of Prosthetics and Orthotics, Faculty of Medicine and \\ Health, Örebro University, Örebro, Sweden
}

Objective: To evaluate the effect of multi-grip myoelectric prosthetic hands on performance of daily activities, pain-related disability and prosthesis use, in comparison with single-grip myoelectric prosthetic hands.

Design: Single-case AB design.

Patients: Nine adults with upper-limb loss participated in the study. All had previous experience of single-grip myoelectric prostheses and were prescribed a prosthesis with multi-grip functions.

Methods: To assess the changes in daily activities, pain-related disability and prosthesis use between single-grip and multi-grip myoelectric prosthetic hands, the Canadian Occupational Performance Measure, Pain Disability Index, and prosthesis wearing time were measured at multiple time-points. Visual assessment of graphs and multi-level linear regression were used to assess changes in the outcome measures.

Results: At 6 months' follow-up self-perceived performance and satisfaction scores had increased, prosthesis wearing time had increased, and painrelated disability had reduced in participants with musculoskeletal pain at baseline. On average, 8 of the 11 available grip types were used. Most useful were the power grip, tripod pinch and lateral pinch. Conclusion: The multi-grip myoelectric prosthetic hand has favourable effects on performance of, and satisfaction with, individually chosen activities, prostheses use and pain-related disability. A durable single-grip myoelectric prosthetic hand may still be needed for heavier physical activities. With structured training, a standard 2-site electrode control system can be used to operate a multi-grip myoelectric prosthetic hand.

Key words: amputation; limb loss; artificial limbs; activities of daily living; pain-related disability; linear models; patient satisfaction.

Accepted Oct 28, 2021; Epub ahead of print Nov 12, 2021

J Rehabil Med 2021; 53: jrm00000

Correspondence address: Cathrine Widehammar, Department of Prosthetics and Orthotics, V-building, Örebro University Hospital, SE-701 85 Örebro, Sweden. E-mail: cathrine.widehammar@regionorebrolan.se

\section{LAY ABSTRACT}

Individuals with upper limb loss are often offered prosthetic hands during the rehabilitation process, to restore body balance and compensate for lack of grip ability. Prosthetic hands with multiple grip functions have been developed to facilitate fine motor skills and enable an ergonomic movement pattern. However, the impact of these hands on the users' daily life has been sparsely studied, and the results have been inconsistent. This study evaluates the effect of multi-grip hands on the performance of daily activities, pain-related disability and prosthesis use, compared to single-grip hands. Based on our results, a multi-grip hand was more useful than a single-grip model for performance of specific, individually chosen activities. Further, prosthesis use increased and pain-related disability was reduced by the use of a multi-grip hand. Multi-grip prosthetic hands seem to fill a gap in prosthetic rehabilitation and facilitate activity performance, and are something clinicians can recommend to their patients.

Tndividuals with upper limb loss due to amputation or reduction deficiency present at birth are often offered prosthetic hands during rehabilitation, in order to restore body balance and compensate for lack of grip ability (1). To improve the usability of the prosthesis, myoelectric prosthetic hands have been developed with multiple grip functions to facilitate fine motor skills. Compared with most single-grip prostheses, many of the multi-grip hands are available in smaller sizes and have a more natural appearance. These improvements have been requested by prosthesis users themselves, since some activities can be difficult to perform with single-grip myoelectric prostheses (2). Furthermore, myoelectric prostheses with multi-grip functions have the potential to enable a natural movement pattern (3), which, over time, may reduce pain due to a reduction in compensatory movements, and avoidance of overuse of the contralateral limb (4-11), or prevent the onset of pain. The new multi-grip functions are intended to increase active participation in society. However, the impact of multi-grip hands on the users' daily life has been little studied, and the results are inconsistent. Some studies 
have shown that multi-grip hand functions bring additional value to users, but also leave a substantial margin for improvement, with some activities still being easier to perform with a single-grip myoelectric hand (12-15). Other studies did not find any improved performance with the multi-grip hands compared with single-grip myoelectric prostheses (14, 16-18). Qualitative studies have shown that the appearance of multi-grip hands is preferred over single-grip prostheses in social situations $(14,19)$, and that the multi-grip design also facilitated the embodiment of the prosthesis (14). However, both users and clinicians reported that many of the multi-grip functions are rarely used (20). There are several possible reasons for this; notably that all functions in the multi-grip hand need to be mastered, which may take time, training and, inevitably, require higher cognitive load (21). Another reason for not using the full potential of the multi-grip hand may be incomplete training (18, 22). With inadequate training the patients may use their multi-grip hand in the same way as they have used a single-grip prosthesis $(23,24)$.

In summary, there may be a mismatch between the patients' wish for better prosthetic devices and their actual use of the new devices. Current knowledge is inconclusive and further studies are needed to support rehabilitation clinicians in their prescription decisions. Questions arise as to whether extensive training in control skills and use of multi-grip functions will facilitate actual use of the prosthesis, and whether this will have an effect on prosthesis users' activity performance and pain-related disability.

The overall aim of this study was therefore to evaluate the effect of multi-grip myoelectric prosthetic hands on the performance of daily activities, painrelated disability and prosthesis use, in comparison with single-grip myoelectric prosthetic hands. A secondary aim was to study the users' ability to learn and use the multi-grip hand functions with a standard 2-site control system.

\section{METHODS}

Both a single-baseline (for ACMC and SHAP data) and a multiplebaseline single-case AB design was used $(25,26)$. In Phase A (baseline), each participant was assessed multiple times, once a week, for performance of daily activities and pain-related disability when using their single-grip myoelectric hand. A total of 3-6 baseline measurements are required to obtain a stable baseline (25), and 3 measurements were found to be sufficient to obtain a stable estimate for these variables as baseline in all participants. Some of the participants were not available for baseline measurements for 3 weeks in a row. This resulted in a baseline period of 3-6 weeks. A single baseline measure for prosthesis skill and use, respectively, were obtained to avoid learning effect from repeated assessments. Subsequently, a multi-grip hand was fitted and training began (the intervention). Phase B (follow-up) started on the second day after the fitting. For this phase the outcome variables were measured using a multi-grip hand on a maximum of 6 occasions over a period of 6 months (Table I). The measurements from phase B are compared with baseline measurements from phase A.

The inclusion criteria were: age 18 years or older, upper limb loss due to amputation or reduction deficiency present at birth, being a previous user of a single-grip myoelectric prosthesis, and having had training in using it, and having currently being prescribed a multi-grip prosthetic hand. A system with an extra, temporary, multi-grip hand of the same type as prescribed was organized for each participant, in order to facilitate compliance with the procedure in the case of breakdowns of the multi-grip hand. In this study, all prostheses are funded by the government and there is no cost for the individual. This study was approved by the Regional Ethics Committee in Uppsala (approval number $2017 / 315$ ). Prior to inclusion, all patients who were prescribed a multi-grip hand between August 2017 and October 2020 received verbal and written information about the study and were invited to participate. All participants signed a written consent.

\section{Measurement instruments}

The Canadian Occupational Performance Measure (COPM) (27) was used to measure performance of daily activities. The COPM is a widely used interviewer-administered generic instrument. In a semi-structured interview, the 5 most important activities that are affected by the health condition are defined by the patient, and the quality of, and satisfaction with, performance of these activities are scored on a 1-10 scale. Based on the scores for these 5 activities, mean scores are calculated for performance quality and satisfaction with performance. A higher score indicates higher quality of performance or greater satisfaction with performance. The minimal clinical important difference is set at 2 points. For this study the validated Swedish version of the COPM (28) was used. All of the chosen activities required fine motor skills and were important in the individual's daily life at home, at work or in leisure time, such as dressing children and using a mobile phone.

The effect on pain-related disability was measured with the Pain Disability Index (PDI) (29). This generic instrument measures the impact of prolonged pain on a person's ability to participate in essential life activities. The PDI is able to detect from low to high levels of pain-related disability on a $0-10$ scale in 7 dimensions. The scores on all the dimensions are summed on a scale of $0-70$, where a higher score indicates more obstacles in essential life activities due to pain. The minimal detectable change (MDC) for PDI is dependent on the baseline score: for scores $\leq 27$, the $\mathrm{MDC}=7$ points; $28-42$, the $\mathrm{MDC}=15$ points; and $\geq 43$, the $\mathrm{MDC}=20$ points.

Prosthesis skill was measured by the Assessment of Capacity for Myoelectric Control (ACMC) (30, 31) and a modified Southampton Hand Assessment Procedure (SHAP) (32). The ACMC is an observation-based assessment of the patient's capacity for control of a myoelectric prosthesis. It consists of 22 items covering specific control skills, with each item being scored on a $0-3$ scale, where 0 is not capable and 3 is extremely capable. The ACMC raw scores are processed through the ACMC website, which transforms the overall score into ACMC units (ranges 0-100). Higher scores indicate greater ability. The intra-rater MDC for ACMC is 0.55 logits (30), which is equal to 2.5 units on the $0-100$ scale. For this study a combination of $2 \mathrm{ACMC}$ activities was used (Mixing a pudding and Setting table). In order for a blinded ACMC researcher (HL) to score the patients, the performance was filmed by a clinician or another researcher $(\mathrm{CW})$. The blinded researcher did not have any connection with the clinic and did not know any of the participants. This researcher viewed the films in a random order and scored the coded patient's capacity for myoelectric control. The 
Table I. Steps in the intervention and the research process: baseline, fitting, training and follow-up

\begin{tabular}{|c|c|c|}
\hline Steps & Action of the treating occupational therapist & Action of the researcher \\
\hline \multicolumn{3}{|l|}{ Phase A: Baseline } \\
\hline \multicolumn{3}{|c|}{ Participant wearing the single-grip hand } \\
\hline \multirow[t]{4}{*}{ Baseline 1 visit } & Casting for a new socket. & Obtaining written informed consent. \\
\hline & \multirow{3}{*}{$\begin{array}{l}\text { Choice of components and design to meet the patient's needs, together } \\
\text { with a certified prosthetist. }\end{array}$} & Collecting participants' characteristics data. \\
\hline & & $\begin{array}{l}\text { Collecting baseline data: self-reported assessment of COPM, } \\
\text { PDI and prosthesis wearing time (h per day). }\end{array}$ \\
\hline & & $\begin{array}{l}\text { Administering modified SHAP and filming ACMC activities } \\
\text { performed with the single-grip hand. }\end{array}$ \\
\hline Baseline 2 phone call & & $\begin{array}{l}\text { Collecting baseline data: self-reported assessment of COPM, } \\
\text { PDI and prosthesis wearing time }\end{array}$ \\
\hline Baseline 3 phone call & & $\begin{array}{l}\text { Collecting baseline data: self-reported assessment of COPM, } \\
\text { PDI and prosthesis wearing time }\end{array}$ \\
\hline
\end{tabular}

Intervention PDI and prosthesis wearing time

Phase B: Follow-up

Participant wearing the multi-grip hand

Day 1 Fitting of multi-grip hand and start of 2-day intensive training:

Information and familiarization with the multi-grip prosthesis functions.

STAIR: integration training (step 1-2) and structured control training (step 3-6).

Day 2 STAIR: integration training (step 1-2), structured control training (step $3-6)$, and activity performance training (step 7-13).

Administering modified SHAP performed with the multi-grip hand.

Filming the ACMC activities Set table and Mixing a pudding performed with the multi-grip hand.

1 week after fitting Phone call follow-up of home training. Verbal support if needed.

with a multi-grip hand

2 weeks after fitting

Repetition of completed STAIR steps and continued training at step 9-13 using the individual COPM activities, starting with the first goal. Homework.

Collecting multi-grip hand data:

Self-reported assessment of PDI and prosthesis wearing time. Administering modified SHAP and filming ACMC activities.

1 month after fitting Repetition of completed STAIR steps and continued training at step 9-13 Collecting multi-grip hand data: using the individual COPM activities: second and third goal. Self-reported assessment of COPM, PDI and prosthesis Homework. wearing time.

Administering modified SHAP and filming ACMC activities.

2 months after fitting Repetition of STAIR control training and continued training at STAIR step Collecting multi-grip hand data: 9-13. Training using the individual COPM activities: fourth and fifth goal. Homework.

Self-reported assessment of COPM, PDI and prosthesis wearing time.

Administering modified SHAP and filming ACMC activities. Collecting multi-grip hand data:

3 months after fitting Repetition of STAIR control training and continued STAIR training according to the patient's needs. Performance training in new individual COPM activities.

Multi-grip settings adjusted if needed. Homework if needed.

6 months after fitting Individual activity training according to the patient's needs.

Self-reported assessment of COPM, PDI and prosthesis wearing time.

Administering modified SHAP and filming ACMC activities. Collecting multi-grip hand data:

Multi-grip settings adjusted if needed.

Self-reported assessment of COPM, PDI, prosthesis wearing time, usefulness and actual use of the 11 grip types.

Administering modified SHAP and filming ACMC activities.

ACMC: Assessment of Capacity for Myoelectric Control; COPM: Canadian Occupational Performance Measure; PDI: Pain Disability Index; SHAP: Southampton Hand Assessment Procedure; STAIR: Stepwise Training for an Advanced and Integrated prosthetic Routine.

modified version of the SHAP test was used to measure the time taken to move objects from the SHAP board by use of, and switch between, the different pre-determined grip types. Five geometric objects from the original SHAP test were used (see Fig. 1 for the modified SHAP board and objects). There is a heavy and a light version of each object. Instead of moving every object, and timing them separately, as in the original SHAP test, participants were instructed to transfer the 5 objects in 1 weight category in a sequence, switching grip type between each object and only measuring the total time (in s) to move all 5 objects. This was registered separately for light objects and heavy objects. A low score indicates greater speed and skill at the task.

A study-specific questionnaire was used to obtain information on prosthesis use, characteristics of the participants and to investigate the perceived usefulness and actual use of each available grip type. Prosthesis use was measured as self-reported wearing time (in $\mathrm{h}$ per day). The usefulness of each of the 11 available grip types was reported on a 1-4 scale, where $1=$ not useful, $2=$ slightly useful, $3=$ very useful and 4=extremely useful. The actual use of the grip types was scored on a 1-4 scale, where $1=$ not used, $2=$ used a little, $3=$ used often and $4=$ used to the maximum.

\section{Procedure}

Following prescription of a multi-grip hand, patients visiting the prosthetic outpatient clinic in Örebro, Sweden were informed about the study and invited to participate. If the patient accepted, the first baseline measurements were taken.

Phase A. Within 3 baseline measures, the first measure (including the study-specific questionnaire) was assessed at the clinic, and the other 2 measures were assessed online or by phone because of the long distance participants had to travel to the clinic. The performance tests, ACMC and modified SHAP were measured once at the clinic, with the participants wearing their single-grip prosthesis.

Intervention. The intervention included fitting a multi-grip hand and a period of training and follow-up. After fitting the multi-grip hand, the participants had an initial 2 days of intensive training at the clinic. Subsequently, $2-3 \mathrm{~h}$ of training was provided at every follow-up: after 2 weeks and after 1, 2, 3 and 6 months. Participants completed a total of $25-30 \mathrm{~h}$ of training. The training was led by an occupational therapist and performed according to the structured training method "Stepwise Training 


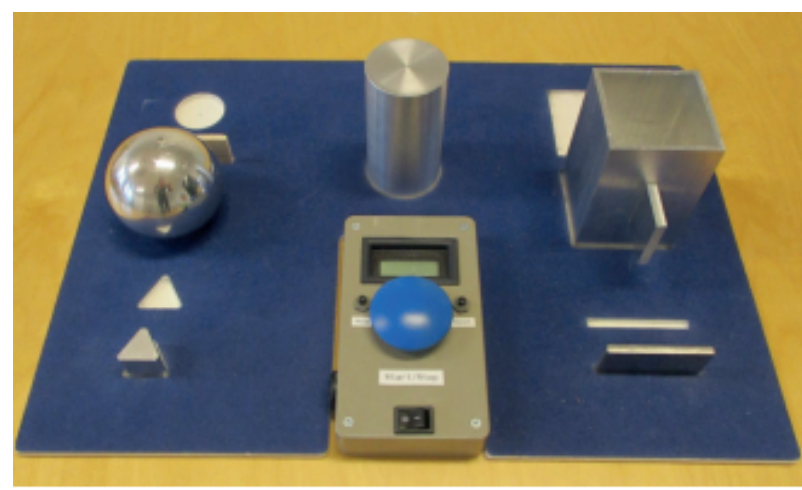

Fig. 1. The Southampton Hand Assessment Procedure (SHAP) board prepared for the modified SHAP test with 5 geometric solid objects (a sphere for spherical grip, a cylinder for power grip, a triangular prism for tripod pinch, a thin rectangular prism for pinch grip, and a cuboid with a thin rectangular prism "handle" for lateral pinch). There is a heavy and a light version of each object. The photograph shows the heavy objects. Each object fits into a matching slot in the board. In the modified SHAP test, the participant moves the 5 objects into their respective slots in a sequence, shifting grip type between each object. The time to move all 5 objects is measured (in s) when the participant presses the blue timer button in the centre; this is timed separately for light objects and heavy objects, monitored by a researcher.

for an Advanced and Integrated prosthetic Routine" (STAIR) (33). The STAIR training includes integration training, control training and training in daily activities. In addition to the intensive training and follow-ups, the participants practised at home the tasks selected through the COPM interview. All participants still had access to their single-grip prosthesis, but were encouraged to use the multi-grip prosthesis as much as they could.

Phase $B$. This phase started on the second day after fitting the new multi-grip hand and continued for up to 6 months. At each follow-up, the participants visited the clinic and were assessed on the following measures: ACMC, modified SHAP, and prosthesis wearing time. The COPM and PDI were measured at the follow-ups after 1, 2, 3 and 6 months. The COPM assessments were based on the same activities that each participant had chosen for the baseline measures. At the 6-month follow-up, the perceived usefulness and actual use of the different grip types were assessed. After the follow-up measures were taken, STAIR-training was implemented.

\section{Analyses}

The changes in COPM, PDI, ACMC, and modified SHAP scores were assessed using both visual assessment of graphs (34) and multilevel linear regression models (35). In the multilevel models, level 2 represented the individual and level 1 represented multiple measurement occasions from baseline to 6 months that were nested within level 2. Data were unbalanced; ACMC had 12/63 missing (19\%), SHAP had 7/63 missing (11\%), COPM had 2/63 missing (3\%), and PDI had $1 / 72$ observation missing (1\%). There was no missingness in covariates. Since multilevel models do not require balanced data for analysis, all available data were utilized for analysis. Random intercept and slope, independent covariance and maximum likelihood methods were used. Two models were fitted, with and without adjustment, with the first including the number of years of prosthesis use and age (as continuous variables) and sex. To assess the possibility of Type I error in relation to the use of maximum likelihood for the small sample size, the analyses were repeated using restricted maximum likelihood with alternative computational methods for the calculation of degrees of freedom, such as the Kenward-Roger procedure (36). Because the results were similar between the different methods, the results obtained from the maximum likelihood method are presented here. Follow-up time was used as a categorical variable, with Phase A (baseline) as the reference. The coefficients indicate differences in scores between baseline and each follow-up occasion in Phase B. Confidence intervals (CIs) not overlapping zero were considered to indicate a statistically significant difference. The PDI and the modified SHAP showed non-constant variability of errors across follow-up time, therefore the analyses were repeated using log transformation (for modified SHAP) and square root transformation (for PDI). As the conclusion remained essentially the same after these transformations, the results from untransformed data are presented here. The perceived usefulness and self-reported actual use of each of the 11 different grip types are presented as the percentage of participants giving each ranking. Two sensitivity analyses were performed. First, 2 individuals with bilateral upper and bilateral lower limb amputations were excluded. Secondly, 2 PDI analyses were performed; 1 with all participants and 1 with the 5 participants who reported pain at baseline. Data analysis was performed using Stata Statistical Software: Release 16 and 17. StataCorp. 2021. College Station, TX: StataCorp LLC.

\section{RESULTS}

\section{Participants}

Nine patients ( 5 males) from the national prosthetic outpatient clinic in Örebro, Sweden were invited and all agreed to participate in the study. They have various causes of limb loss and various prosthesis wearing time (see Table II). All study participants were fitted with a bebionic multi-grip hand from Ottobock, Vienna, Austria using 2-site direct control and were followed up for 6 months. (Fig. 2).
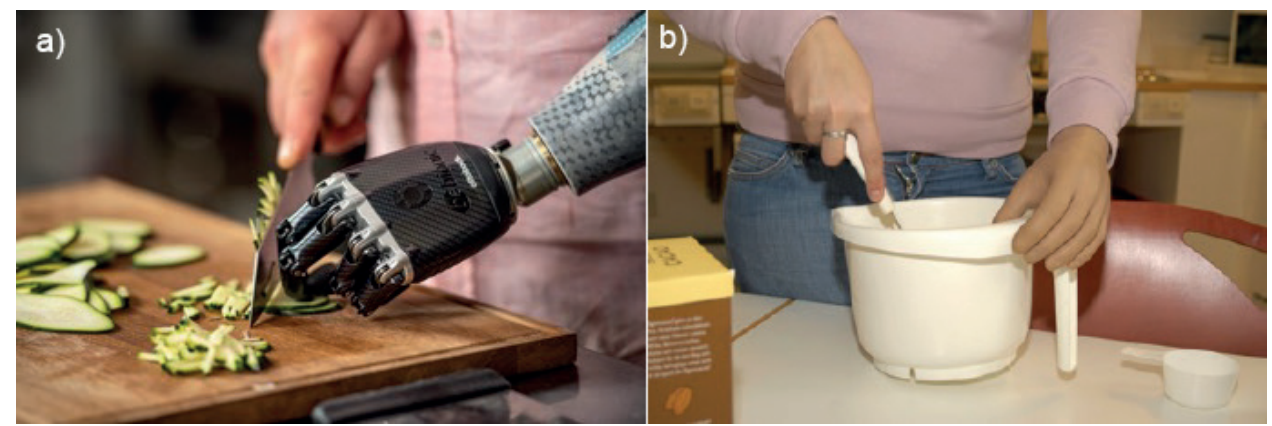

Fig. 2. a) Multi-grip myoelectric prosthetic hand bebionic from Ottobock, Vienna Austria. b) Standard single-grip myoelectric prosthetic hand Variplus Speed from Ottobock, Vienna Austria. 
Table II. Participants' characteristics

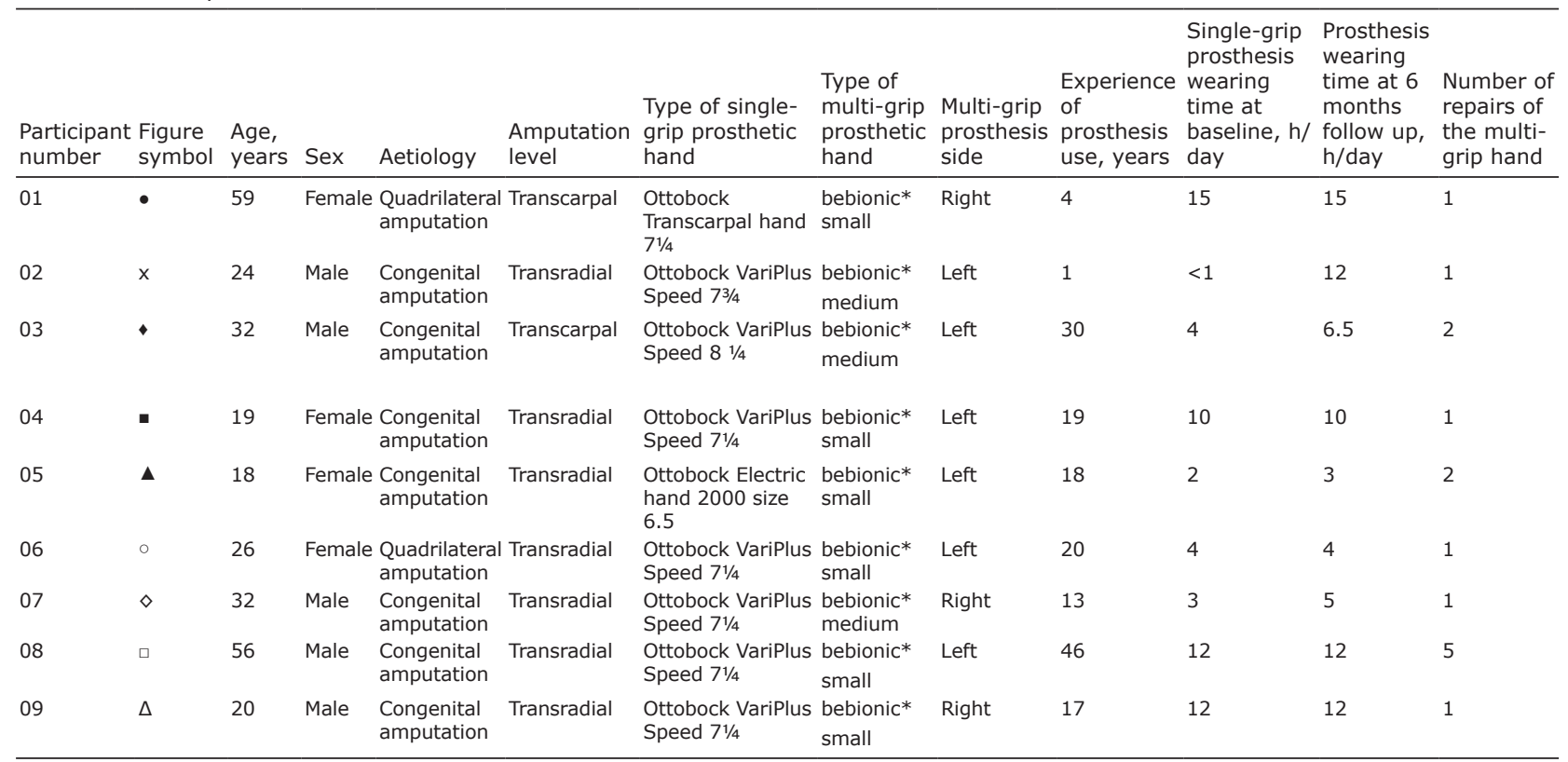

*Ottobock bebionic hand has 14 grip types or positions to choose from. Each individual can choose 8 of these to be programmed: 4 in the primary grip pattern and 4 in the secondary grip pattern. The thumb is moved manually into opposed or non-opposed position. Pressing a button on the back of the hand changes between the grip patterns. To change between grips within each pattern a trigger signal (for example double open signal or co-contraction) is used. In addition, 2 grip types and 1 position can be used without programming. The bebionic hand from Ottobock, Vienna, Austria, has 14 grip types or positions for each user.

\section{Performance and satisfaction}

The graphs show that both occupational performance and satisfaction scores in COPM increased for all individuals after using the multi-grip hand (Fig. 3a and Fig. 3b). Multilevel regression-adjusted models showed that, after 3 months, quality of performance scores increased, by a mean of 3.9 points $(95 \% \mathrm{CI}=3.2-4.6)$ and satisfaction with performance scores increased by 4.9 points $(\mathrm{CI}=4.0-5.7)$ (Table III). Unadjusted estimates were similar to the adjusted estimates (Table SI for unadjusted analyses).

\section{Pain-related disability}

Five participants reported that musculoskeletal pain was limiting their participation in essential life activities at baseline (Fig. 4). This activity limitation generally declined after fitting a multi-grip hand. In contrast, 1 participant who reported no pain-related disability at baseline reported some limitation at the 1-month follow-up due to increased wearing time, although at the subsequent follow-up, this participant's PDI score returned to 0 . Furthermore, none of the 4 participants who gave a PDI score of 0 at baseline reported any pain-related disability

Table III. Adjusted coefficients, $95 \%$ confidence intervals (95\% CI) and $p$-values using multilevel linear regression models for Canadian Occupational Performance Measure (COPM), Pain Disability Index (PDI), Assessment of Capacity for Myoelectric Control (ACMC) and modified Southampton Hand Assessment Procedure (SHAP) scores

\begin{tabular}{|c|c|c|c|c|c|c|c|c|}
\hline & & $\begin{array}{l}\text { COPM } \\
\text { Performance }\end{array}$ & $\begin{array}{l}\text { COPM } \\
\text { Satisfaction }\end{array}$ & PDI & PDI $(n=5)^{*}$ & ACMC & $\begin{array}{l}\text { Modified SHAP } \\
\text { Light objects, } \\
\text { sec }\end{array}$ & $\begin{array}{l}\text { Modified SHAP } \\
\text { Heavy objects, } \\
\text { sec }\end{array}$ \\
\hline & $\begin{array}{l}\text { Data collection } \\
\text { time-point }\end{array}$ & $\begin{array}{l}\text { Coefficient } \\
(95 \% \mathrm{CI})\end{array}$ & $\begin{array}{l}\text { Coefficient } \\
(95 \% \mathrm{CI})\end{array}$ & $\begin{array}{l}\text { Coefficient } \\
(95 \% \mathrm{CI})\end{array}$ & $\begin{array}{l}\text { Coefficient } \\
(95 \% \mathrm{CI})\end{array}$ & $\begin{array}{l}\text { Coefficient } \\
(95 \% \mathrm{CI})\end{array}$ & $\begin{array}{l}\text { Coefficient } \\
(95 \% \mathrm{CI})\end{array}$ & $\begin{array}{l}\text { Coefficient } \\
(95 \% \mathrm{CI})\end{array}$ \\
\hline Phase A & Baseline & Reference & Reference & Reference & Reference & Reference & Reference & Reference \\
\hline \multirow[t]{5}{*}{ Phase B } & 2 days & $\begin{array}{l}\text { No data } \\
\text { collected }\end{array}$ & $\begin{array}{l}\text { No data } \\
\text { collected }\end{array}$ & No data collected & No data collected & $\begin{array}{l}-18.5(-24.5 \text { to } 12.4) \\
p<0.001\end{array}$ & $\begin{array}{l}26.3(8.1 \text { to } 44.4) \\
p=0.005\end{array}$ & $\begin{array}{l}28.3(12.2 \text { to } 44.3) \\
p=0.001\end{array}$ \\
\hline & 1 month & $\begin{array}{l}3.0(2.1 \text { to } 3.8) \\
p<0.001\end{array}$ & $\begin{array}{l}3.8(2.7 \text { to } 4.9) \\
p<0.001\end{array}$ & $\begin{array}{l}-2.0(-9.9 \text { to } 5.9) \\
p=0.620\end{array}$ & $\begin{array}{l}-4.6(-18.1 \text { to } 8.9) \\
p=0.504\end{array}$ & $\begin{array}{l}-4.2(-8.6 \text { to } 0.3) \\
p=0.068\end{array}$ & $\begin{array}{l}9.3(2.9 \text { to } 15.8) \\
p=0.004\end{array}$ & $\begin{array}{l}12.1(-3.1 \text { to } 27.4) \\
p=0.119\end{array}$ \\
\hline & 2 months & $\begin{array}{l}3.5(2.9 \text { to } 4.0) \\
p<0.001\end{array}$ & $\begin{array}{l}4.5(3.6 \text { to } 5.4) \\
p<0.001\end{array}$ & $\begin{array}{l}-4.0(-10.8 \text { to } 2.8) \\
p=0.249\end{array}$ & $\begin{array}{l}-7.2(-18.4 \text { to } 4.0) \\
p=0.209\end{array}$ & $\begin{array}{l}-4.8(-9.5 \text { to }-0.2) \\
p=0.042\end{array}$ & $\begin{array}{l}5.0(0.4 \text { to } 9.6) \\
p=0.033\end{array}$ & $\begin{array}{l}1.2(-8.4 \text { to } 10.9) \\
p=0.801\end{array}$ \\
\hline & 3 months & $\begin{array}{l}3.9(3.2 \text { to } 4.6) \\
p<0.001\end{array}$ & $\begin{array}{l}4.9(4.0 \text { to } 5.7) \\
p<0.001\end{array}$ & $\begin{array}{l}-9.0(-16.3 \text { to }-1.7) \\
p=0.015\end{array}$ & $\begin{array}{l}-14.4(-23.0 \text { to }-5.8) \\
p=0.001\end{array}$ & $\begin{array}{l}-1.4 \quad(-6.1 \text { to } 3.2) \\
p=0.545\end{array}$ & $\begin{array}{l}2.3(-2.3 \text { to } 6.9) \\
p=0.330\end{array}$ & $\begin{array}{l}3.4(-6.3 \text { to } 13.1) \\
p=0.494\end{array}$ \\
\hline & 6 months & $\begin{array}{l}4.3(3.6 \text { to } 4.9) \\
p<0.001\end{array}$ & $\begin{array}{l}4.8(3.9 \text { to } 5.7) \\
p<0.001\end{array}$ & $\begin{array}{l}-7.7(-14.0 \text { to }-1.3) \\
p=0.018\end{array}$ & $\begin{array}{l}-13.8(-21.8 \text { to }-5.8) \\
p=0.001\end{array}$ & $\begin{array}{l}-2.5 \quad(-7.8 \text { to } 2.8) \\
p=0.359\end{array}$ & $\begin{array}{l}6.5(-5.2 \text { to } 18.1) \\
p=0.275\end{array}$ & $\begin{array}{l}-3.7(-13.4 \text { to } 6.0) \\
p=0.454\end{array}$ \\
\hline
\end{tabular}

*Includes only the 5 participants who reported pain-related disability in the Pain Disability Index at the baseline measurements. $95 \%$ CI: $95 \%$ confidence interval. The estimates are adjusted for years of use and age (as continuous variables) and sex. The coefficients indicate difference of the outcome value at a given time-point compared with the baseline. 
p. 6 of 11 C. Widehammar et al.

a

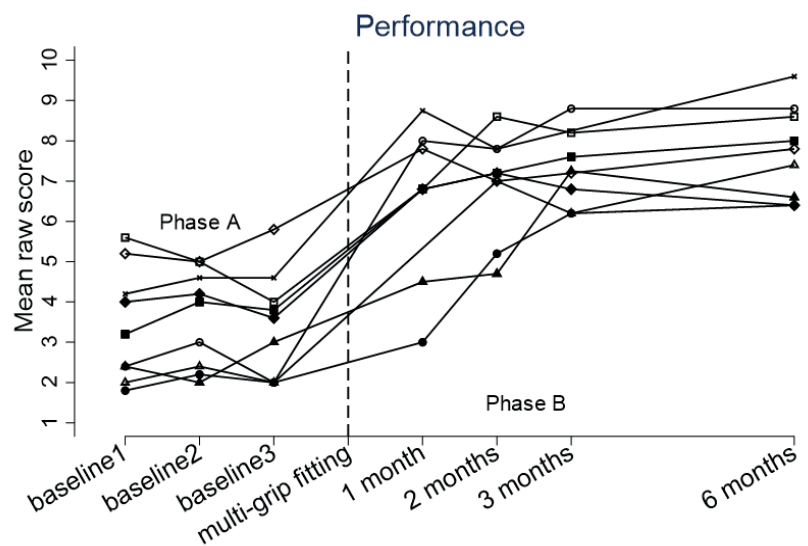

Measurement occasions

b

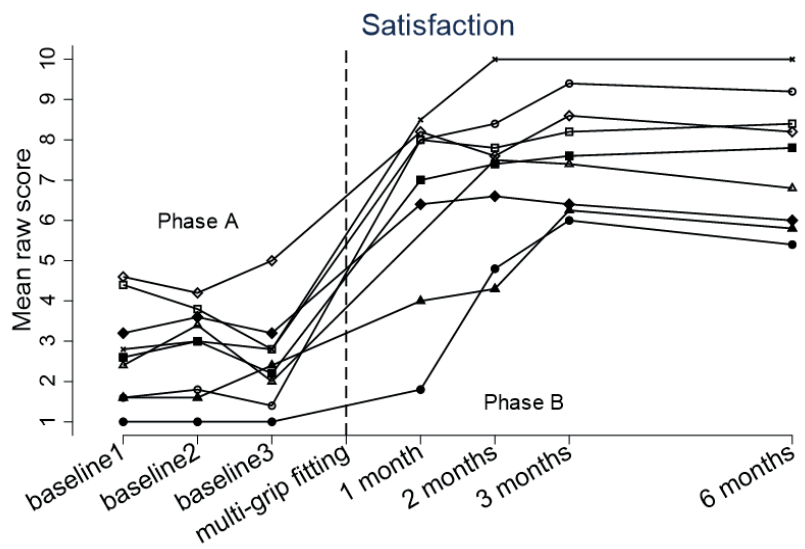

\section{Measurement occasions}

Fig. 3. Visual assessment of graphs of quality of and satisfaction with performance, as measured with the Canadian Occupational Performance Measure (COPM). (a) Quality of performance; (b) satisfaction with performance. Raw scores range from 1 to 10, with 10 representing the best possible score. (Phase $A=$ baseline with the single-grip hand, Phase $B=$ follow-up after fitting the multi-grip hand.) Note: symbols referring to patient IDs: $\bullet=01, x=02, \bullet=03, \boldsymbol{\bullet}=04, \boldsymbol{\Delta}=05, \circ=06, \diamond=07, \square=08$, and $\Delta=09$. See Table II for description of participants' characteristics.

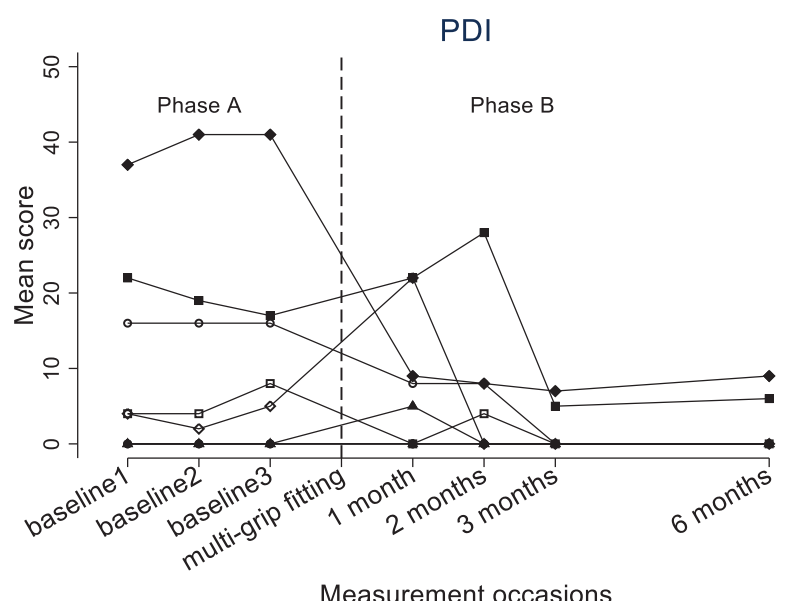

Fig. 4. Visual assessment of graphs of the Pain Disability Index (PDI) scores for 9 participants. Scores range from 0 to 70 . Higher scores indicate more pain-related limitation in the performance of daily activities. Four of the participants (represented by a black triangle, white triangle, black circle and $X$ ) were pain free at baseline and thus their lines are overlaid at the score of 0 . (Phase $A=$ baseline with the single-grip hand, Phase $B$

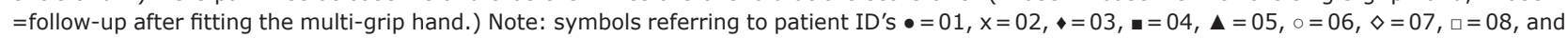
$\Delta=09$. See Table II for description of participants' characteristics. 


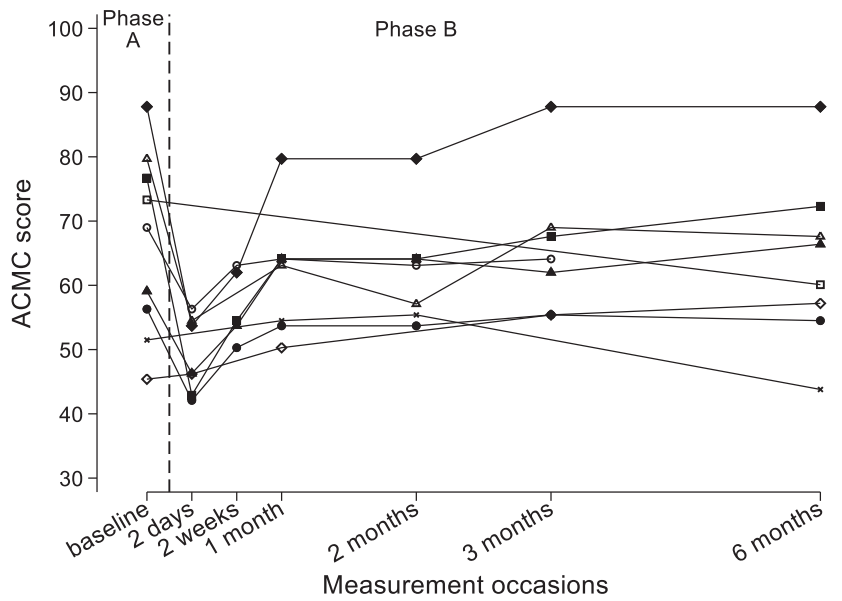

Fig. 5. Visual assessment of graphs of the Assessment of Capacity for Myoelectric Control (ACMC) scores, demonstrating that most participants decreased in skill after fitting of the multi-grip hand, but regained their skill after using it for 3 months. A high score indicates greater skill in myoelectric prosthesis use, maximum score $=100$. Phase $A$ included 1 baseline measure to control against learning effects. (Phase $A=b a s e l i n e$ with the single-grip hand, Phase $B=$ follow-up after fitting the multi-grip hand.) Note: symbols referring to patient IDs $\bullet=01, x=02, \bullet=03, \boldsymbol{m}=04$, $\Delta=05, \diamond=06, \diamond=07, \square=08$, and $\Delta=09$. See Table II for description of participants' characteristics.

a)

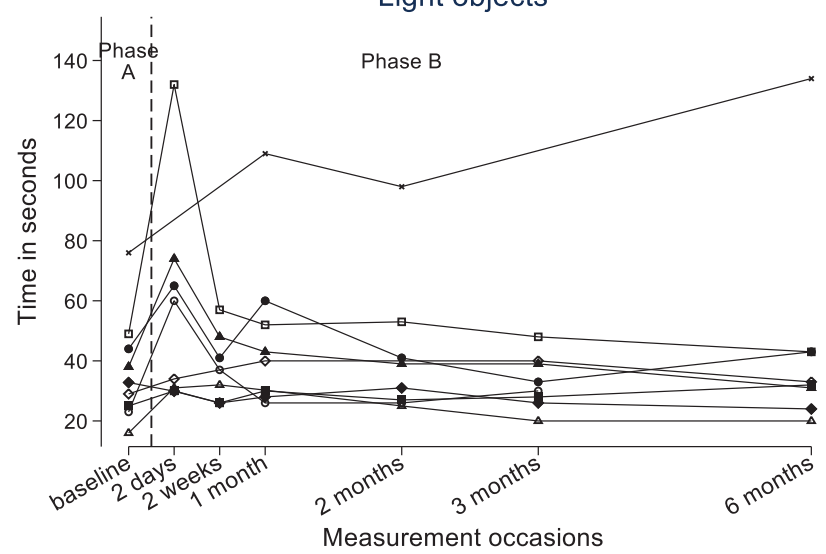

b)

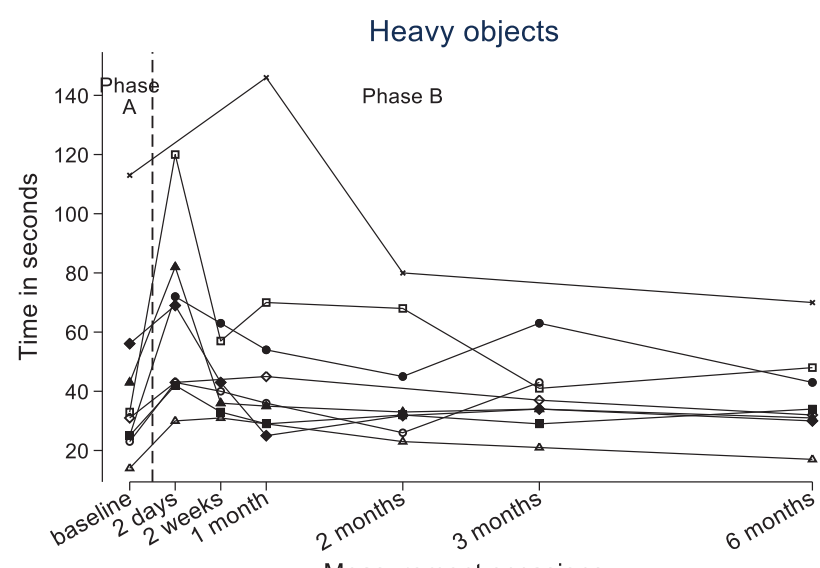

Fig. 6. Visual assessment of graphs of the modified Southampton Hand Assessment Procedure (SHAP) scores. (a) Performance with light objects; (b) performance with heavy objects. The participant's performance is measured (in s), with a low score indicating greater skill in switching between grip types and using different grip types to move objects. Phase A included 1 baseline measure to control against learning effects. (Phase $\mathrm{A}=$ baseline with the single-grip hand, Phase $\mathrm{B}=$ follow-up after fitting the multi-grip hand.) Note: symbols referring to patient ID's $\bullet=01, \mathrm{x}=02$, $\downarrow=03, \boldsymbol{\square}=04, \boldsymbol{\Delta}=05, \circ=06, \diamond=07, \square=08$, and $\Delta=09$. See Table II for description of participants' characteristics. 
at the later follow-ups, and at the 6-month follow-up the number of participants reporting any pain-related disability had decreased from 5 to 2 . In the adjusted multilevel analyses, focussing on the 5 participants who reported pain-related disability at baseline, it was found that, compared with baseline, their PDI mean score decreased significantly, by a mean of $-14.4(\mathrm{CI}=-23.0$ to -5.8$)$ at the 3-month follow-up, and by $-13.8(\mathrm{CI}=-21.8$ to -5.8$)$ at the 6-month follow-up (Table III). A similar pattern was observed when all participants were analysed, although the magnitude of coefficient became much smaller. At the 3- and 6-month follow-ups the PDI mean score decreased from baseline by -9.0 and -7.7 , respectively.

\section{Prosthetic skill}

Initially, when the participants were fitted a multi-grip hand, their skill in prosthesis control (ACMC scores) decreased compared with their baseline performance with the single-grip hand (Fig. 5). However, after 3 months, the score of most of the participants increased to a level similar as with the single-grip hand. Adjusted multilevel analyses showed that, although the mean ACMC score at the 6-month follow-up was lower than the baseline score by -2.5 , this was not statistically significant (CI $=-7.8$ to 2.8 ) (Table III).

The time to perform the modified SHAP test became longer 2 days after fitting the multi-grip hand, compared with baseline with the single-grip hand. However, by the measurement after 2 weeks, it decreased to a similar level as with the single-grip hand (Fig. 6a and Fig. 6b). Indeed, compared with baseline, at the 2-day follow-up in the adjusted model, there was a statistically significant increase, of approximately $30 \mathrm{~s}$, for both light $(\mathrm{CI}=8.1-44.4)$ and heavy $(\mathrm{CI}=12.2-44.3)$ objects (Table III). However, in the later follow-ups, the time decreased gradually, and at the 6-month follow-up the mean time to perform the modified SHAP

a)

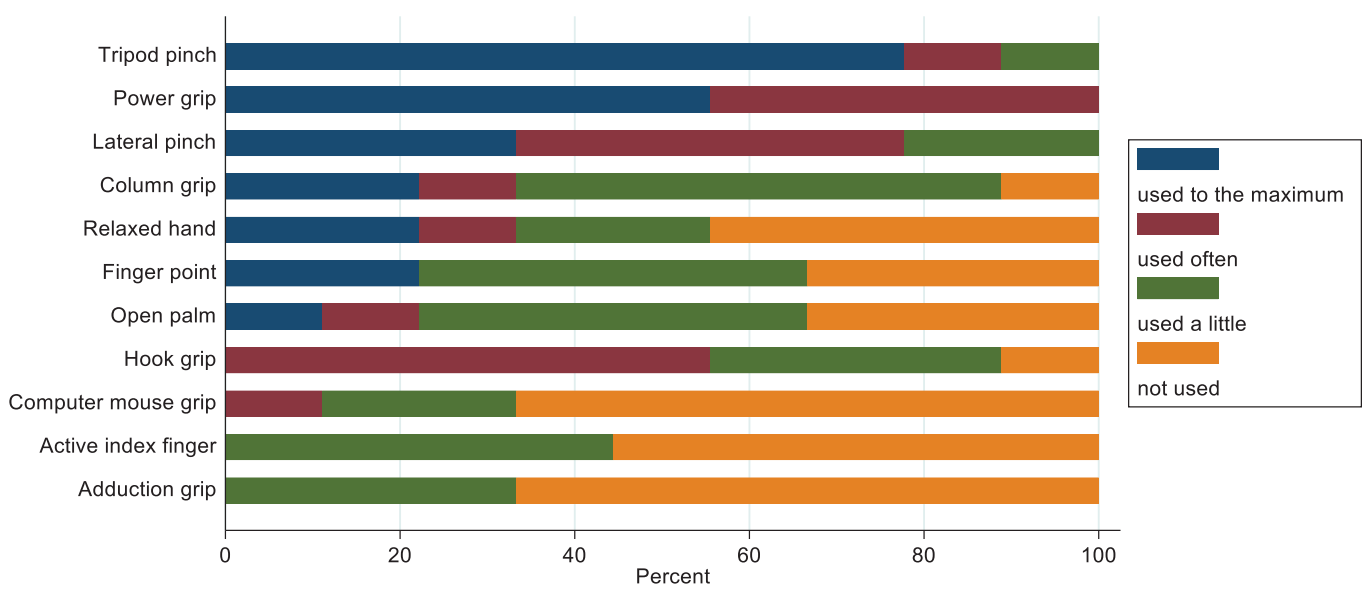

b)

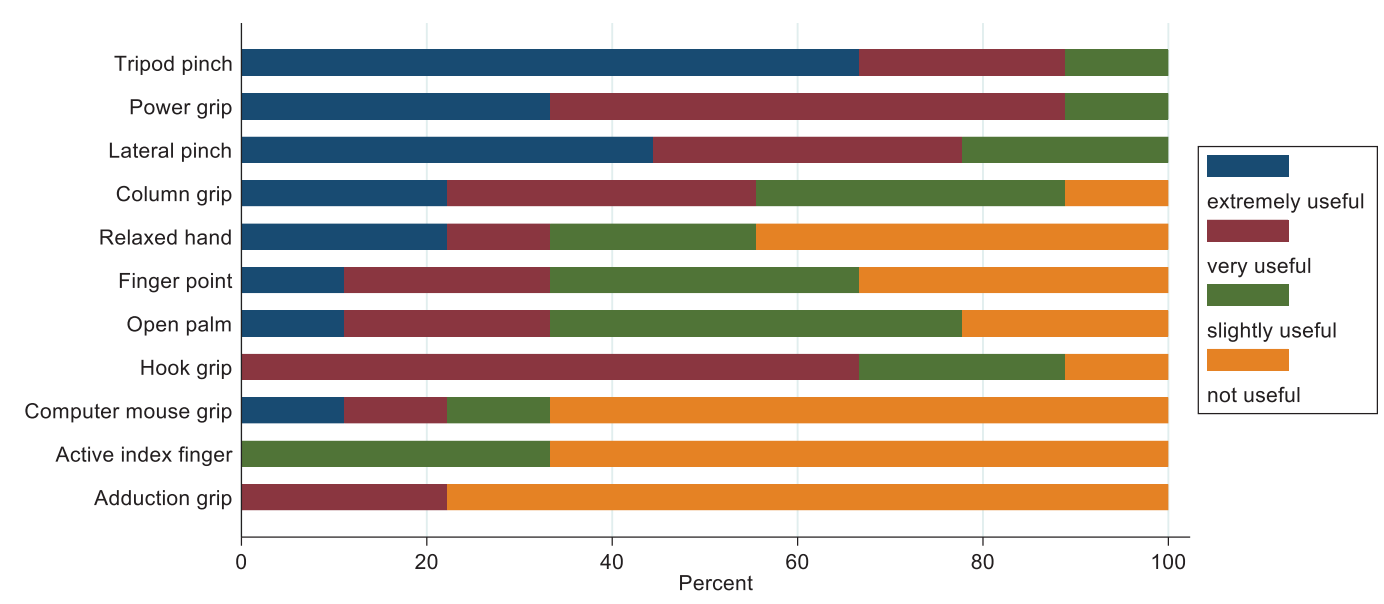

Fig. 7. User evaluation ( $n=9$ ) of their use of the 11 grip types and hand positions (tripod pinch, power grip, active index finger, lateral pinch, finger point, computer mouse grip, column grip, relaxed hand, adduction grip, hook grip, open palm) in the multi-grip hand at the 6-month follow-up, showing the percentage of participants giving each ranking. (a) Actual use; (b) perceived usefulness. 
was not statistically significantly different from the baseline with the single-grip hand; $7 \mathrm{~s}$ slower for the light objects ( $\mathrm{CI}=-5.2$ to 18.1) and $4 \mathrm{~s}$ faster for the heavy objects $(\mathrm{CI}=-13.4$ to 6.0$)$.

\section{Prosthesis use and perceived usefulness of multi- grip features}

Participants increased their self-reported prosthesis wearing time after switching to a multi-grip hand, from a mean of 6.9 hours a day with single-grip hand to $8.8 \mathrm{~h}$ a day with the multi-grip hand at the 6-month follow-up (Table II). The median number of grip types used was 8 out of 11 (range 7-10). Grip types that were considered most useful and were used most were the power grip, tripod pinch and lateral pinch (Fig. 7a and Fig. 7b).

\section{Sensitivity analysis}

When 2 individuals with quadrilateral limb amputations were excluded from the analyses, there were small declines in effect sizes for COPM performance and increase for ACMC. Furthermore, in the early follow-up assessments, effect sizes for SHAP heavily declined while they increased in later follow-up occasions. However, the pattern of association remained similar (Table SII).

\section{Secondary finding}

All participants reported problems with the durability of the multi-grip hand. These were broken prosthesis fingers, battery failures and problems with the software. The median number of repairs was 1 (range 1-5) during the 6-month trial and no participant was free from technical problems with the device (Table II). The system with temporary hands did not work as expected, and most of the participants had a short period of non-use of the multi-grip hand during the trial.

\section{DISCUSSION}

To our knowledge, this is the first intervention study evaluating myoelectric multi-grip prosthetic hands with a multilevel baseline-design and a follow-up of 6 months. The results are positive overall: compared with myoelectric single-grip hands, performance and satisfaction with the multi-grip hands increased, and pain-related disability decreased in participants who reported that musculoskeletal pain restricted their participation in daily life activities. The participants learned to switch efficiently between grips and they used many of the optional hand grip types and positions. However, the poor durability of the multi-grip hands was problematic for daily use.
The choice of instruments to measure the outcome of an intervention is important. In contrast to previous studies (12-18) that have used various questionnaires to measure differences between prosthetic hand models, it was decided to use a person-centred measure, the COPM. Since the most important daily activities vary between different people, and between prosthesis users, depending on life situations, interests and occupations, we believe that person-centred measures, such as the COPM, give the best information on how the multi-grip prosthesis affects an individual's daily activities. Questionnaires that are not person-centred and ask about activities that the person may never want or need to perform may negatively influence the outcome of a study. This may explain the more positive results for multi-grip hands in the current study.

In contrast to earlier research (20), the current results show that, even though the participants used a 2-site electrode control system, many of the grip functions were used. Today, another method to control a multigrip hand has been introduced: pattern recognition control systems (37) that use multiple electrodes. Pattern recognition systems have been developed to facilitate the control of the multi-grip, multi-function prosthesis by simplifying the switching between grip types and, therefore, might also have a positive effect on the use of different grip types, although this has not yet been shown.

Not surprisingly, the 3 grip types that were preferred and most used by the participants were the tripod pinch, the power grip and the lateral pinch. According to earlier research, these grip types are most commonly used by human hands (38), and, consequently, were the ones most used by prosthesis users (39). The substantial use of the additional grip types by the participants in this study was unexpected. For individuals with bilateral amputations, who may be entirely dependent on a prosthesis for performing fine motor skills, the opportunity to have several optional grip types is especially important. The results showing that several grip types were also used by participants with unilateral amputation was unexpected. For the activities that require fine motor skills, the multi-grip functions were perfect, but for activities involving heavier objects the participants still needed a more durable single-grip prosthesis to avoid breakdowns and long repair times. This is in line with earlier studies comparing multi-grip with single-grip prosthetic hands $(12,15)$. The poor durability of the multi-grip hands was troublesome, both for the participants' daily use of the hands and for the study. Despite the problems with durability, and although the participants were not reminded to wear the prosthesis, all participants wore their multi-grip hands for more hours than their single-grip hands and wanted to keep the multi-grip hand for different reasons. 
Home-training was encouraged, and hence this might have affected wearing time. Further studies are needed into the user's perspective of using multi-grip hands in daily life, in order to provide valuable information to both clinicians and prosthetic developers.

For the participants who initially reported that musculoskeletal pain was limiting their participation in essential life activities, pain-related disability was reduced by use of the multi-grip hand. However, when all participants were included in the analysis, the pattern of decline was similar, but with a smaller magnitude of association. There may be several reasons for the reduction in pain-related disability. Firstly, the multigrip functions enable a more natural movement pattern. In particular, training to use the lateral pinch for better position and grip reduces the need for compensatory movements in the shoulder and trunk. Secondly, the participants increased their prosthesis wearing time after being fitted with the multi-grip hand. By using the prosthesis more, overuse of the contralateral hand may decrease, resulting in less overuse pain. However, further research is needed to confirm this hypothesis.

It is a challenge to change individuals' habits when, for example, changing between hands or control systems. The significance of re-training has been highlighted before and becomes clear when experienced myoelectric prosthesis users change to multi-grip hands (24). By using individually chosen activities that were meaningful for the participants, they were motivated and learned to perform the daily tasks by use of the multi-grip hand. Similar to previous studies with multi-grip hands, the current results show that, after completing training, the experienced users were still skilled in myoelectric control $(15,18)$. This is in contrast to other studies, in which activities were found to be easier to perform with a single-grip hand (12-15) and a low use of the multi-grip functions of the new hands was reported (20). The training used for the current study focuses not only on learning to switch between grip types, but also on learning which grip type is most effective for use in different situations in the person's daily life. This individually tailored training may explain the improvements in the participants' performance and the reduction in pain-related disability in this study. However, this requires verification in further studies.

\section{Methodological considerations}

A single-case design with a multiple baseline $A B$ design was chosen for this study. This is preferable for studying changes over time $(25,26)$. Behavioural changes take time, and to be able to study changes in the participants' activity performance and pain-related disability, the follow-up time was long, 6 months after the intervention. The time-points for follow-ups were set closer together at the beginning, since it was assumed that most changes would occur at the beginning of the treatment. It turned out, that the chosen design enabled to capture and describe the changes.

The study sample consisted predominantly of experienced users of myoelectric prostheses. Experience is expected to facilitate ability in how to switch between different grip types, but it was a challenge to change the participants' earlier habits. However, the long-term training made the participants overcome their previous habits and establish new ones for control of the multigrip hand. Hence, this procedure is recommended for future studies with similar research aims. The study participants included 2 persons with quadrilateral amputation. The performance of these persons was expected to be different from that of the 7 persons with unilateral amputation. However, the results show that the persons with bilateral amputation followed the same pattern as those with unilateral amputation.

The SHAP test has been criticized for inducing learning effects (40), which may influence the outcome. To prevent this, at least 2 weeks were allowed to elapse between assessments with the SHAP objects. However, the test was performed in the same order in every participant, light objects first and then heavy objects, which may have influenced the results and explain the greater improvement with the heavy objects. The ACMC is validated for users of myoelectric, but, not for multi-grip, hands. Therefore, certain aspects of control of a multi-grip hand, such as choosing the appropriate grip and switching between grip types were not evaluated. However, using the ACMC was useful to demonstrate the development of control. Filming the ACMC activities and having a blinded assessor strengthened the validity of the ACMC scores.

There were some missing data, mainly in the performance tests, due to break-down and repair of the multi-grip hands. Although participants had access to temporary hands, it was sometimes not possible to conduct the tests, since the temporary hands also broke down a few times. The repair time may have negatively affected the result, since the participants were left without a multi-grip hand for up to 2 weeks. However, the missing data appeared randomly distributed across participants and follow-up occasions, reducing the impact on the results. Furthermore, for some outcomes, baseline data were collected only once. It is therefore less certain that those baselines reflect well the true baseline values. However, it was observed that the values tended to stay similar when other outcome variables were measured multiple times and most of the participants had used their prosthesis for many years. Data in the patients' files show that their prosthesis use and skill were very stable.

In conclusion, a multi-grip myoelectric hand prosthesis can be more useful than a single-grip model for performance of specific, individually chosen activities. Use of the multi-grip functions may reduce pain-related disability. Multi-grip prosthetic hands may thus fill a 
gap in prosthetic rehabilitation, but a durable single-grip hand may still be needed for heavier physical activities. With structured training a standard 2-site electrode control system can be used to operate a multi-grip hand.

\section{REFERENCES}

1. Cancio JM, Ikeda AJ, Barnicott SL, Childers WL, Alderete JF, Goff BJ. Upper extremity amputation and prosthetics care across the active duty military and veteran populations. Phys Med Rehabil Clin N Am 2019; 30: 73-87.

2. Widehammar C, Pettersson I, Janeslätt G, et al. The influence of environment: Experiences of users of myoelectric arm prosthesis - a qualitative study. Prosthet Orthot Int 2017; 42: 28-36.

3. Resnik L, Huang HH, Winslow A, et al. Evaluation of EMG pattern recognition for upper limb prosthesis control: a case study in comparison with direct myoelectric control. ] Neuroeng Rehabil 2018; 15: 23.

4. Reed D. Understanding and meeting the needs of farmers with amputations. Orthop Nurs 2004; 23: 397-402, 404-395.

5. Datta D, Selvarajah K, Davey N. Functional outcome of patients with proximal upper limb deficiency - acquired and congenital. Clin Rehabil 2004; 18: 172-177.

6. Postema SG, Bongers RM, Brouwers MA, et al. Musculoskeletal complaints in transverse upper limb reduction deficiency and amputation in the Netherlands: prevalence, predictors, and effect on health. Arch Phys Med Rehabil 2016; 97: 1137-1145.

7. Resnik L, Ekerholm S, Borgia M, et al. A national study of Veterans with major upper limb amputation: survey methods, participants, and summary findings. PLoS One 2019; 14: e0213578. 2019/03/15.

8. Jones L, Davidson J. Save that arm: a study of problems in the remaining arm of unilateral upper limb amputees. Prosthet Orthot Int 1999; 23: 55-58.

9. Hanley MA, Ehde DM, Jensen $M$, et al. Chronic pain associated with upper-limb loss. Am J Phys Med Rehabil 2009; 88: 742.

10. Østlie K, Franklin RJ, Skjeldal OH, et al. Musculoskeletal pain and overuse syndromes in adult acquired major upper-limb amputees. Arch Phys Med Rehabil 2011; 92: 1967-1973. e1961.

11. Gambrell CR. Overuse syndrome and the unilateral upper limb amputee: consequences and prevention. J Prosthet Orthot 2008; 20: 126-132.

12. Pröbsting E, Kannenberg A, Conyers DW, et al. Ease of activities of daily living with conventional and multigrip myoelectric hands. J Prosthet Orthot 2015; 27: 46-52.

13. Popovic I, Cutti A, Ryan T, et al. Do multi-grip hands increase function and patient satisfaction when compared to traditional myoelectric hands? Canadian Prosthet Orthot J 2018; 1 .

14. Luchetti M, Verni G, Sacchetti R, et al. Impact of Michelangelo prosthetic hand: Findings from a crossover longitudinal study. J Rehabil Res Dev 2015; 52: 605.

15. Van Der Niet Otr O, Reinders-Messelink HA, Bongers RM, et al. The i-LIMB hand and the DMC plus hand compared: a case report. Prosthet Orthot Int 2010; 34: 216-220.

16. Kyberd P. Assessment of functionality of multifunction prosthetic hands. J Prosthet Orthot 2017; 29: 103-111.

17. Loiret I, Sanamane V, Touillet A, et al. Assessment of multigrip prosthetic hand by a crossover longitudinal study. Ann Phys Med Rehabil 2017; 60: e34.

18. Van Der Niet O, Bongers RM, Van Der Sluis CK. Functionality of i-LIMB and i-LIMB Pulse hands: Case report. J Rehabil Res Dev 2013; 50.

19. Kerver N, van Twillert S, Maas B, et al. User-relevant factors determining prosthesis choice in persons with major unilateral upper limb defects: a meta-synthesis of qualitative literature and focus group results. PLoS One
2020; 15: e0234342.

20. Franzke AW, Kristoffersen MB, Bongers RM, et al. Users' and therapists' perceptions of myoelectric multi-function upper limb prostheses with conventional and pattern recognition control. PLoS One 2019; 14: e0220899.

21. Resnik LJ, Acluche F, Lieberman Klinger S. User experience of controlling the DEKA Arm with EMG pattern recognition. PLoS One 2018; 13: e0203987.

22. Resnik L, Meucci MR, Lieberman-Klinger S, et al. Advanced upper limb prosthetic devices: implications for upper limb prosthetic rehabilitation. Arch Phys Med Rehabil 2012; 93: 710-717.

23. Roche AD, Vujaklija I, Amsuss $S$, et al. A Structured rehabilitation protocol for improved multifunctional prosthetic control: a case study. J Vis Exp 2015: e52968.

24. Johnson SS and Mansfield E. Prosthetic training: upper limb. Phys Med Rehabil Clin N Am 2014; 25: 133-151.

25. Lane JD, Gast DL. Visual analysis in single case experimental design studies: Brief review and guidelines. Neuropsychol Rehabil 2014; 24: 445-463.

26. Dallery J, Cassidy RN, Raiff BR. Single-case experimental designs to evaluate novel technology-based health interventions. J Med Internet Res 2013; 15: e22.

27. Law M, Baptiste S, McColl M, et al. The Canadian Occupational Performance Measure: an outcome measure for occupational therapy. Can J Occup Ther 1990; 57: 82-87.

28. Wressle E, Samuelsson K, Henriksson C. Responsiveness of the Swedish version of the Canadian occupational performance measure. Scand J Occup Ther 1999; 6: 84-89.

29. Tait RC, Pollard CA, Margolis RB, et al. The Pain Disability Index: psychometric and validity data. Arch Phys Med Rehabil 1987; 68: 438-441.

30. Lindner HY, Langius-Eklöf A, Hermansson L M. Test-retest reliability and rater agreements of the Assessment of Capacity for Myoelectric Control version 2.0. J Rehabil Res Dev. 2014; 51: 635-44.

31. Lindner HY, Linacre JM, Norling Hermansson LM. Assessment of capacity for myoelectric control: Evaluation of construct and rating scale. J Rehabil Med 2009; 41: 467-474.

32. Light CM, Chappell PH, Kyberd PJ. Establishing a standardized clinical assessment tool of pathologic and prosthetic hand function: normative data, reliability, and validity. Arch Phys Med Rehabil 2002; 83: 776-783.

33. Widehammar C. Results study IV - the training method STAIR, page 53-56; In: Benefits and use of myoelectric arm prostheses: outcomes, influencing factors and experiences. Doctoral dissertation. Örebro: Örebro University; 2021. Available from: http://oru.divaportal.org/smash/ get/diva2:1539440/FULLTEXT01.pdf.

34. Lobo MA, Moeyaert M, Cunha AB, et al. Single-case design, analysis, and quality assessment for intervention research. J Neurol Phys Ther 2017; 41: 187.

35. Baek EK, Moeyaert M, Petit-Bois M, et al. The use of multilevel analysis for integrating single-case experimental design results within a study and across studies. Neuropsychol Rehabil 2014; 24: 590-606.

36. McNeish D. Small sample methods for multilevel modeling: a colloquial elucidation of REML and the Kenward-Roger correction. Multivariate Behavioral Research 2017; 52: 661-670.

37. Mastinu E, Ahlberg J, Lendaro $\mathrm{E}$, et al. An alternative myoelectric pattern recognition approach for the control of hand prostheses: a case study of use in daily life by a dysmelia subject. IEEE J Translat Eng Health Med 2018; 6: 1-12.

38. Vergara M, Sancho-Bru JL, Gracia-Ibáñez V, et al. An introductory study of common grasps used by adults during performance of activities of daily living. J Hand Ther 2014; 27: 225-234.

39. Wang S, Hsu CJ, Trent L, et al. Evaluation of performancebased outcome measures for the upper limb: a comprehensive narrative review. Phys Med Rehabil 2018; 10: 951-962. e953.

40. Vasluian E, Bongers RM, Reinders-Messelink HA, et al. Learning effects of repetitive administration of the Southampton Hand Assessment Procedure in novice prosthetic users. J Rehabil Med 2014; 46: 788-797. 
Supplementary material to article by C. Widehammar et al. "Effect of multi-grip myoelectric prosthetic hands on daily activities, pain-related disability and prosthesis use compared with single-grip myoelectric prostheses: A single-case study"

Table SI. Unadjusted coefficients, 95\% confidence intervals (95\% CI) and $p$-values using multilevel linear regression models for Canadian Occupational Performance Measure (COPM), Pain Disability Index (PDI), Assessment of Capacity for Myoelectric Control (ACMC) and modified Southampton Hand Assessment Procedure (SHAP) scores

\begin{tabular}{|c|c|c|c|c|c|c|c|c|}
\hline \multirow{2}{*}{\multicolumn{2}{|c|}{$\begin{array}{l}\text { Data } \\
\text { collection } \\
\text { time-point }\end{array}$}} & \multirow{2}{*}{$\begin{array}{l}\text { COPM } \\
\text { Performance } \\
\text { Coefficient } \\
(95 \% \mathrm{CI})\end{array}$} & \multirow{2}{*}{$\begin{array}{l}\text { COPM } \\
\text { Satisfaction } \\
\text { Coefficient } \\
(95 \% \mathrm{CI})\end{array}$} & \multirow{2}{*}{$\begin{array}{l}\text { PDI } \\
\text { Coefficient } \\
(95 \% \mathrm{CI})\end{array}$} & \multirow{2}{*}{$\begin{array}{l}\text { PDI }(n=5)^{*} \\
\text { Coefficient } \\
(95 \% \mathrm{CI})\end{array}$} & \multirow{2}{*}{$\begin{array}{l}\text { ACMC } \\
\text { Coefficient } \\
(95 \% \mathrm{CI})\end{array}$} & \multirow{2}{*}{$\begin{array}{l}\text { Modified SHAP } \\
\text { Light objects, } \\
\text { sec } \\
\text { Coefficient } \\
(95 \% \mathrm{CI})\end{array}$} & \multirow{2}{*}{$\begin{array}{l}\text { Modified SHAP } \\
\text { Heavy objects, } \\
\text { sec } \\
\begin{array}{l}\text { Coefficient } \\
(95 \% \mathrm{CI})\end{array}\end{array}$} \\
\hline & & & & & & & & \\
\hline Phase A & Baseline & Reference & Reference & Reference & Reference & Reference & Reference & Reference \\
\hline \multirow[t]{6}{*}{ Phase B } & 2 days & $\begin{array}{l}\text { No data } \\
\text { collected }\end{array}$ & $\begin{array}{l}\text { No data } \\
\text { collected }\end{array}$ & $\begin{array}{l}\text { No data } \\
\text { collected }\end{array}$ & $\begin{array}{l}\text { No data } \\
\text { collected }\end{array}$ & $\begin{array}{l}-18.9(-25.1 \text { to }-12.7) \\
p<0.001\end{array}$ & $\begin{array}{l}26.3(8.2 \text { to } 44.3) \\
p=0.004\end{array}$ & $\begin{array}{l}28.3 \\
(12.5 \text { to } 44.1) \\
p<0.001\end{array}$ \\
\hline & 2 weeks & $\begin{array}{l}\text { No data } \\
\text { collected }\end{array}$ & $\begin{array}{l}\text { No data } \\
\text { collected }\end{array}$ & $\begin{array}{l}\text { No data } \\
\text { ollected }\end{array}$ & $\begin{array}{l}\text { No data } \\
\text { collected }\end{array}$ & $\begin{array}{l}-12.9(-19.0 \text { to }-6.8) \\
p<0.001\end{array}$ & $\begin{array}{l}7.7(2.7 \text { to } 12.6) \\
p=0.002\end{array}$ & $\begin{array}{l}8.7(-1.5 \text { to } 18.8) \\
p=0.094\end{array}$ \\
\hline & 1 month & $\begin{array}{l}3.0(2.1 \text { to } 3.8) \\
p<0.001\end{array}$ & $\begin{array}{l}3.8(2.7 \text { to } 4.9) \\
p<0.001\end{array}$ & $\begin{array}{l}-2.0(-9.9 \text { to } 5.9) \\
p=0.620\end{array}$ & $\begin{array}{l}-4.6(-18.2 \text { to } 9.0) \\
p=0.507\end{array}$ & $\begin{array}{l}-4.6(-9.0 \text { to }-0.1) \\
p=0.045\end{array}$ & $\begin{array}{l}9.3(2.8 \text { to } 15.8) \\
p=0.005\end{array}$ & $\begin{array}{l}12.1 \\
(-3.3 \text { to } 27.4) \\
p=0.123\end{array}$ \\
\hline & 2 months & $\begin{array}{l}3.5(2.9 \text { to } 4.0) \\
p<0.001\end{array}$ & $\begin{array}{l}4.5(3.6 \text { to } 5.4) \\
p<0.001\end{array}$ & $\begin{array}{l}-4.0(-10.8 \text { to } 2.8) \\
p=0.249\end{array}$ & $\begin{array}{l}-7.2(-18.6 \text { to } 4.2) \\
p=0.216\end{array}$ & $\begin{array}{l}-5.3(-10.0 \text { to }-0.7) \\
p=0.025\end{array}$ & $\begin{array}{l}5.0(0.4 \text { to } 9.6) \\
p=0.035\end{array}$ & $\begin{array}{l}1.0(-8.7 \text { to } 10.8) \\
p=0.833\end{array}$ \\
\hline & 3 months & $\begin{array}{l}3.9(3.3 \text { to } 4.6) \\
p<0.001\end{array}$ & $\begin{array}{l}4.9(4.1 \text { to } 5.6) \\
p<0.001\end{array}$ & $\begin{array}{l}-9.0(-16.2 \text { to }-1.7) \\
p=0.015\end{array}$ & $\begin{array}{l}-14.4(-23.1 \text { to }-5.7) \\
p=0.001\end{array}$ & $\begin{array}{l}-1.8(-6.5 \text { to } 2.8) \\
p=0.441\end{array}$ & $\begin{array}{l}2.3(-2.3 \text { to } 6.9) \\
p=0.333\end{array}$ & $\begin{array}{l}3.4(-6.3 \text { to } 13.1) \\
p=0.496\end{array}$ \\
\hline & 6 months & $\begin{array}{l}4.3(3.7 \text { to } 4.9) \\
p<0.001\end{array}$ & $\begin{array}{l}4.8(3.9 \text { to } 5.7) \\
p<0.001\end{array}$ & $\begin{array}{l}-7.7(-14.0 \text { to }-1.3) \\
p=0.018\end{array}$ & $\begin{array}{l}-13.8(-21.9 \text { to }-5.7) \\
p=0.001\end{array}$ & $\begin{array}{l}-2.5(-7.5 \text { to } 2.5) \\
p=0.334\end{array}$ & $\begin{array}{l}6.5(-5.2 \text { to } 18.2) \\
p=0.275\end{array}$ & $\begin{array}{l}-3.6 \\
(-13.3 \text { to } 6.1) \\
p=0.466\end{array}$ \\
\hline
\end{tabular}

*Includes only the 5 participants who reported pain-related disability in the Pain Disability Index at the baseline measurements. $95 \%$ CI: $95 \%$ confidence interval. The coefficients indicate difference of the outcome value at a given time-point compared with baseline. 
Supplementary material to article by C. Widehammar et al. "Effect of multi-grip myoelectric prosthetic hands on daily activities, pain-related disability and prosthesis use compared with single-grip myoelectric prostheses: A single-case study"

Table SII. Adjusted coefficients, 95\% confidence intervals and $p$-values using multilevel linear regression models for Canadian Occupational Performance Measure (COPM), Pain Disability Index (PDI), Assessment of Capacity for Myoelectric Control (ACMC) and modified Southampton Hand Assessment Procedure (SHAP) scores, excluding 2 individuals with bilateral upper and bilateral lower limb amputations

\begin{tabular}{|c|c|c|c|c|c|c|c|c|}
\hline & \multirow{2}{*}{$\begin{array}{l}\text { Data } \\
\text { collection } \\
\text { time-point }\end{array}$} & \multirow{2}{*}{$\begin{array}{l}\text { COPM } \\
\text { Performance } \\
\begin{array}{l}\text { Coefficient } \\
(95 \% \mathrm{CI})\end{array}\end{array}$} & \multirow{2}{*}{$\begin{array}{l}\text { COPM } \\
\text { Satisfaction } \\
\text { Coefficient } \\
(95 \% \mathrm{CI})\end{array}$} & \multirow{2}{*}{$\begin{array}{l}\text { PDI } \\
\text { Coefficient } \\
(95 \% \mathrm{CI})\end{array}$} & \multirow{2}{*}{$\begin{array}{l}\text { PDI }(n=5)^{*} \\
\text { Coefficient } \\
(95 \% \mathrm{CI})\end{array}$} & \multirow{2}{*}{$\begin{array}{l}\text { ACMC } \\
\text { Coefficient } \\
(95 \% \mathrm{CI})\end{array}$} & \multirow{2}{*}{$\begin{array}{l}\text { Modified SHAP } \\
\text { Light objects, } \\
\text { sec } \\
\text { Coefficient } \\
(95 \% \mathrm{CI})\end{array}$} & \multirow{2}{*}{$\begin{array}{l}\text { Modified SHAP } \\
\text { Heavy objects, } \\
\text { sec } \\
\text { Coefficient } \\
(95 \% \mathrm{CI})\end{array}$} \\
\hline & & & & & & & & \\
\hline Phase A & Baseline & Reference & Reference & Reference & Reference & Reference & Reference & Reference \\
\hline \multirow[t]{5}{*}{ Phase B } & 2 days & $\begin{array}{l}\text { No data } \\
\text { collected }\end{array}$ & $\begin{array}{l}\text { No data } \\
\text { collected }\end{array}$ & $\begin{array}{l}\text { No data } \\
\text { collected }\end{array}$ & $\begin{array}{l}\text { No data } \\
\text { collected }\end{array}$ & $\begin{array}{l}-21.1 \\
(-28.5 \text { to }-13.7) \\
p<0.001\end{array}$ & $\begin{array}{l}25.5(1.6 \text { to } 49.4) \\
p=0.037\end{array}$ & $\begin{array}{l}26.8(6.7 \text { to } 46.9) \\
p=0.009\end{array}$ \\
\hline & 2 weeks & $\begin{array}{l}\text { No data } \\
\text { collected }\end{array}$ & $\begin{array}{l}\text { No data } \\
\text { collected }\end{array}$ & $\begin{array}{l}\text { No data } \\
\text { collected }\end{array}$ & $\begin{array}{l}\text { No data } \\
\text { collected }\end{array}$ & $\begin{array}{l}-16.7(-23.8 \text { to }-9.5) \\
p<0.001\end{array}$ & $\begin{array}{l}8.8(3.0 \text { to } 14.6) \\
p=0.003\end{array}$ & $\begin{array}{l}3.0(-8.0 \text { to } 14.1) \\
p=0.594\end{array}$ \\
\hline & 1 month & $\begin{array}{l}2.9(2.2 \text { to } 3.5) \\
p<0.001\end{array}$ & $\begin{array}{l}3.9(3.1 \text { to } 4.6) \\
p<0.001\end{array}$ & $\begin{array}{l}-1.4(-11.4 \text { to } 8.6) \\
p=0.779\end{array}$ & $\begin{array}{l}-3.8(-20.8 \text { to } 13.3) \\
p=0.667\end{array}$ & $\begin{array}{l}-4.5(-10.1 \text { to } 1.2) \\
p=0.120\end{array}$ & $\begin{array}{l}9.1(3.0 \text { to } 15.1) \\
p=0.003\end{array}$ & $\begin{array}{l}9.7(-10.2 \text { to } 29.6) \\
p=0.340\end{array}$ \\
\hline & 2 months & $\begin{array}{l}3.2(2.6 \text { to } 3.9) \\
p<0.001\end{array}$ & $\begin{array}{l}4.2(3.3 \text { to } 5.1) \\
p<0.001\end{array}$ & $\begin{array}{l}-4.0(-12.6 \text { to } 4.6) \\
p=0.362\end{array}$ & $\begin{array}{l}-7.0(-21.4 \text { to } 7.4) \\
p=0.342\end{array}$ & $\begin{array}{l}-5.2(-11.9 \text { to } 1.6) \\
p=0.132\end{array}$ & $\begin{array}{l}6.7(1.4 \text { to } 12.0) \\
p=0.012\end{array}$ & $\begin{array}{l}-1.2(-11.5 \text { to } 9.2) \\
p=0.824\end{array}$ \\
\hline & 3 months & $\begin{array}{l}3.5(2.9 \text { to } 4.1) \\
p<0.001\end{array}$ & $\begin{array}{l}4.4(3.9 \text { to } 5.0) \\
p<0.001\end{array}$ & $\begin{array}{l}-9.3(-18.3 \text { to }-0.4) \\
p=0.041\end{array}$ & $\begin{array}{l}-14.0(-25.0 \text { to }-3.0) \\
p=0.013\end{array}$ & $\begin{array}{l}-1.5(-7.5 \text { to } 4.5) \\
p=0.622\end{array}$ & $\begin{array}{l}3.8(-1.4 \text { to } 9.1) \\
p=0.154\end{array}$ & $\begin{array}{l}-4.9(-15.2 \text { to } 5.5) \\
p=0.357\end{array}$ \\
\hline
\end{tabular}

*Includes only the 5 participants who reported pain-related disability in the Pain Disability Index at the baseline measurements. $95 \%$ CI: $95 \%$ confidence interval. The estimates are adjusted for years of use and age (as continuous variables) and sex. The coefficients indicate difference of the outcome value at a given timepoint compared with baseline. 